\title{
Cholecystokinin receptor-1 mediates the inhibitory effects of exogenous cholecystokinin octapeptide on cellular morphine dependence
}

\author{
Di Wen ${ }^{1}$, Chun-ling Ma ${ }^{1 *}$, Ya-jing Zhang ${ }^{2}$, Yan-xin Meng ${ }^{1}$, Zhi-yu Ni ${ }^{1}$, Shu-jin Li ${ }^{1}$ and Bin Cong ${ }^{1}$
}

\begin{abstract}
Background: Cholecystokinin octapeptide (CCK-8), the most potent endogenous anti-opioid peptide, has been shown to regulate the processes of morphine dependence. In our previous study, we found that exogenous CCK-8 attenuated naloxone induced withdrawal symptoms. To investigate the precise effect of exogenous CCK-8 and the role of cholecystokinin (CCK) 1 and/or 2 receptors in morphine dependence, a SH-SY5Y cell model was employed, in which the $\mu$-opioid receptor, CCK1/2 receptors, and endogenous CCK are co-expressed.
\end{abstract}

Results: Forty-eight hours after treating SH-SY5Y cells with morphine $(10 \mu \mathrm{M})$, naloxone $(10 \mu \mathrm{M})$ induced a cAMP overshoot, indicating that cellular morphine dependence had been induced. The CCK receptor and endogenous CCK were up-regulated after chronic morphine exposure. The CCK2 receptor antagonist (LY-288,513) at 1-10 $\mu \mathrm{M}$ inhibited the naloxone-precipitated CAMP overshoot, but the CCK1 receptor antagonist $(L-364,718)$ did not. Interestingly, CCK-8 (0.1-1 $\mu \mathrm{M})$, a strong CCK receptor agonist, dose-dependently inhibited the naloxoneprecipitated CAMP overshoot in SH-SY5Y cells when co-pretreated with morphine. The L-364,718 significantly blocked the inhibitory effect of exogenous CCK-8 on the CAMP overshoot at 1-10 $\mu \mathrm{M}$, while the LY-288,513 did not. Therefore, the CCK2 receptor appears to be necessary for low concentrations of endogenous CCK to potentiate morphine dependence in SH-SY5Y cells. An additional inhibitory effect of CCK-8 at higher concentrations appears to involve the CCK1 receptor.

Conclusions: This study reveals the difference between exogenous CCK-8 and endogenous CCK effects on the development of morphine dependence, and provides the first evidence for the participation of the CCK1 receptor in the inhibitory effects of exogenous CCK-8 on morphine dependence.

Keywords: Cholecystokinin octapeptide, CCK1 receptor, CCK2 receptor, Morphine, Cellular dependence, CAMP overshoot

\section{Background}

Opioids are not only potent analgesics but are also drugs of abuse, which greatly limits their clinical use. Chronic use of opioids results in the development of tolerance and dependence. Recent studies suggest that non-opioid systems could be important targets for the treatment of opioid dependence [1,2]. Antagonism of opioid effects by endogenous anti-opioid peptides is common [3]. Cholecystokinin (CCK) was initially identified as a gastrointestinal hormone, and was subsequently found in the

\footnotetext{
*Correspondence: chunlingma@126.com

'Department of Forensic Medicine, Hebei Medical University, Hebei Key

Laboratory of Forensic Medicine, Shijiazhuang 050017, PR China

Full list of author information is available at the end of the article
}

central and peripheral nervous systems. It occurs as various sized peptides, including 4, 8, 33, 39 and 58 amino acid forms [4]. Cholecystokinin octapeptide (CCK-8) is the most potent endogenous anti-opioid peptide [5]. For example, morphine treatments enhance the overflow of CCK, whereas CCK- 8 and its analogues attenuate the analgesic effects of morphine [6-8]. Furthermore, studies have demonstrated that the CCK system modulates a variety of physiological processes, and that CCK- 8 interacts with the GABAergic and dopaminergic systems. Thus, CCK-8 plays a significant role in a wide range of central actions including memory and drug reward [9-12]. Overlap in the distributions of CCK and opioid receptors may be observed in some anatomical regions

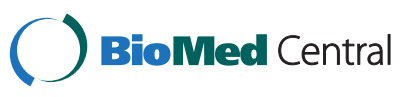


that are involved in opioid antinociception and dependence [13]. These findings indicate that the CCK system is related to the modulation of morphine tolerance and dependence.

The administration of CCK receptor antagonists can prevent or reverse tolerance to systemic exogenous opioids or electroacupuncture-induced analgesia, as well as suppress morphine withdrawal syndromes [14-16]. Interestingly, CCK receptor activation can reverse morphine tolerance [17]. We previously found that chronic pretreatment with exogenous CCK-8 significantly inhibited naloxone-precipitated withdrawal symptoms, which is the same effect as CCK-receptor antagonists $[18,19]$. These phenomena suggest that the effects of exogenous CCK- 8 are distinct from the role of endogenous CCK. With regard to dosage, CCK- 8 was able to prevent morphine dependence at high, but not low, concentrations [20]. However, no studies have reported a dose-response curve of CCK-8 on morphine dependence. On the basis of the pharmacological properties and specificities for ligand binding, CCK receptors have been identified for the CCK1 and CCK2 receptor subtypes [21]. The expression pattern of these CCK receptors in mammals appears to be tissue-specific [22]. Several studies have revealed that two different CCK receptors (CCK1 and CCK2) have opposing influences on behavioural and hormonal actions $[23,24]$. Thus, CCK receptor subtypes that mediate the inhibitory effects of exogenous CCK- 8 on morphine dependence remain to be determined.

The biological basis of tolerance and dependence induced by chronic exposure to opioids is thought to be due to molecular, cellular, and neural network adaptations. On the cellular level, opioid dependence is characterised by a significant elevation of adenylyl cyclase (AC) activity after drug withdrawal, which is a regulatory phenomenon termed "AC supersensitivity" or "cAMP overshoot" [25-27]. A cAMP overshoot represents an opioid-dependent state in vitro and has been utilised in the study of the effects of morphine dependence [28]. This present study evaluates the effects of CCK-8 on the AMP overshoot based on a cellular model and aims to clarify the exact effects of exogenous CCK-8. In addition, the subtypes of $\mathrm{CCK}$ receptor that mediate the function of CCK- 8 on morphine dependence are also investigated.

\section{Results}

\section{In vitro model of morphine dependence}

The SH-SY5Y cell line was used to examine the effects of CCK-8 on cellular morphine dependence. It is well established that up-regulation of the adenylate cyclase effector system represents an in vitro opioid-dependent state. Thus, withdrawal of opioids following chronic treatment leads to a cAMP overshoot, which is also referred to 'CAMP super-sensitisation', and is an in vitro model of the abstinence state. In the present study, the level of cAMP increased $1.57( \pm 0.08)$-folds after morphine treatment $(10 \mu \mathrm{M} ; 48 \mathrm{~h})$, and was elevated to 3.09 $( \pm 0.289)$-folds after naloxone treatment, compared to the non-treated cells $(10 \mu \mathrm{M} ; 15 \mathrm{~min})$. The analysis of the data obtained from the cAMP tests with two-way ANOVA revealed a significant morphine and naloxone interaction $\left(\mathrm{F}_{1,8}=53.718, \mathrm{P}<0.001\right)$ on the cAMP level, which indicated that the cAMP overshoot was significantly induced by chronic morphine exposure following naloxone precipitation (Figure 1).

\section{The effect of chronic morphine exposure on the endogenous CCK system}

The expression of the opioid and CCK system in SH-SY5Y cells was initially confirmed. Our results revealed that the $\mu$-opioid, CCK1 and CCK2 receptors were co-expressed in SH-SY5Y cells, and that SH-SY5Y cells contained endogenous CCK (Figure 2A). The effect of chronic morphine exposure on the expression of the endogenous CCK system in SH-SY5Y cells was measured. The expression of the CCK1/CCK2 receptor and endogenous CCK mRNA were up-regulated 2.51( \pm 0.56$)$-, 6.10 $( \pm 0.91)$ - and $4.87( \pm 1.08)$-fold $(P=0.004, P<0.001$ and $P<0.001$, respectively) after $10 \mu \mathrm{M}$ morphine treatment for $48 \mathrm{~h}$ (Figure 2B).

\section{The effect of CCK receptor antagonists on naloxone- precipitated CAMP overshoot in SH-SY5Y cells after chronic morphine exposure}

CCK-8 is the most potent endogenous anti-opioid peptide and endogenous CCK expression is up-regulated

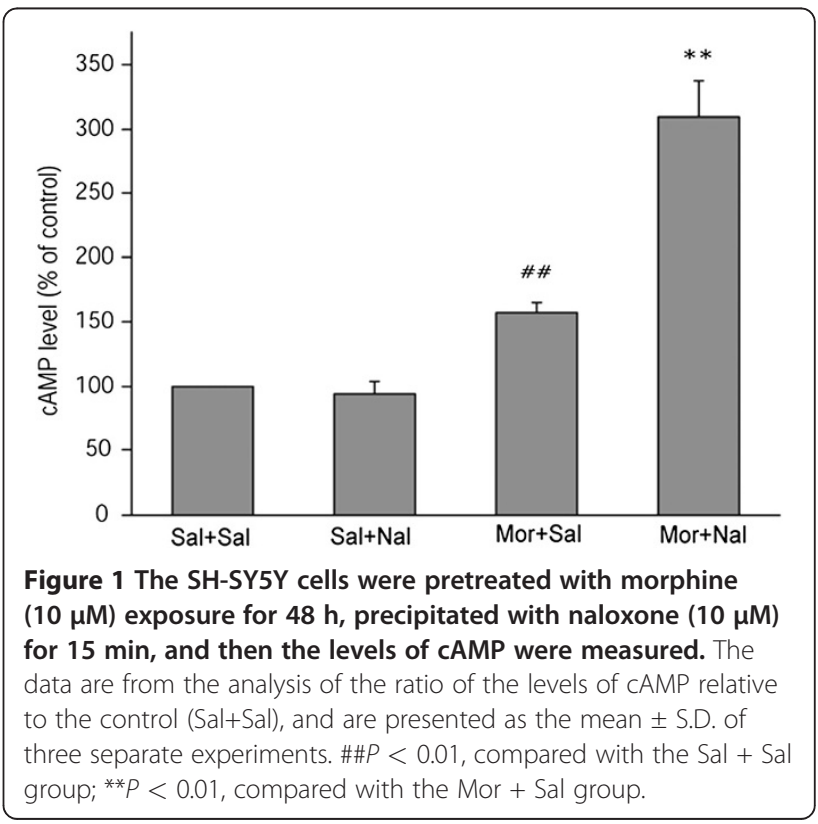




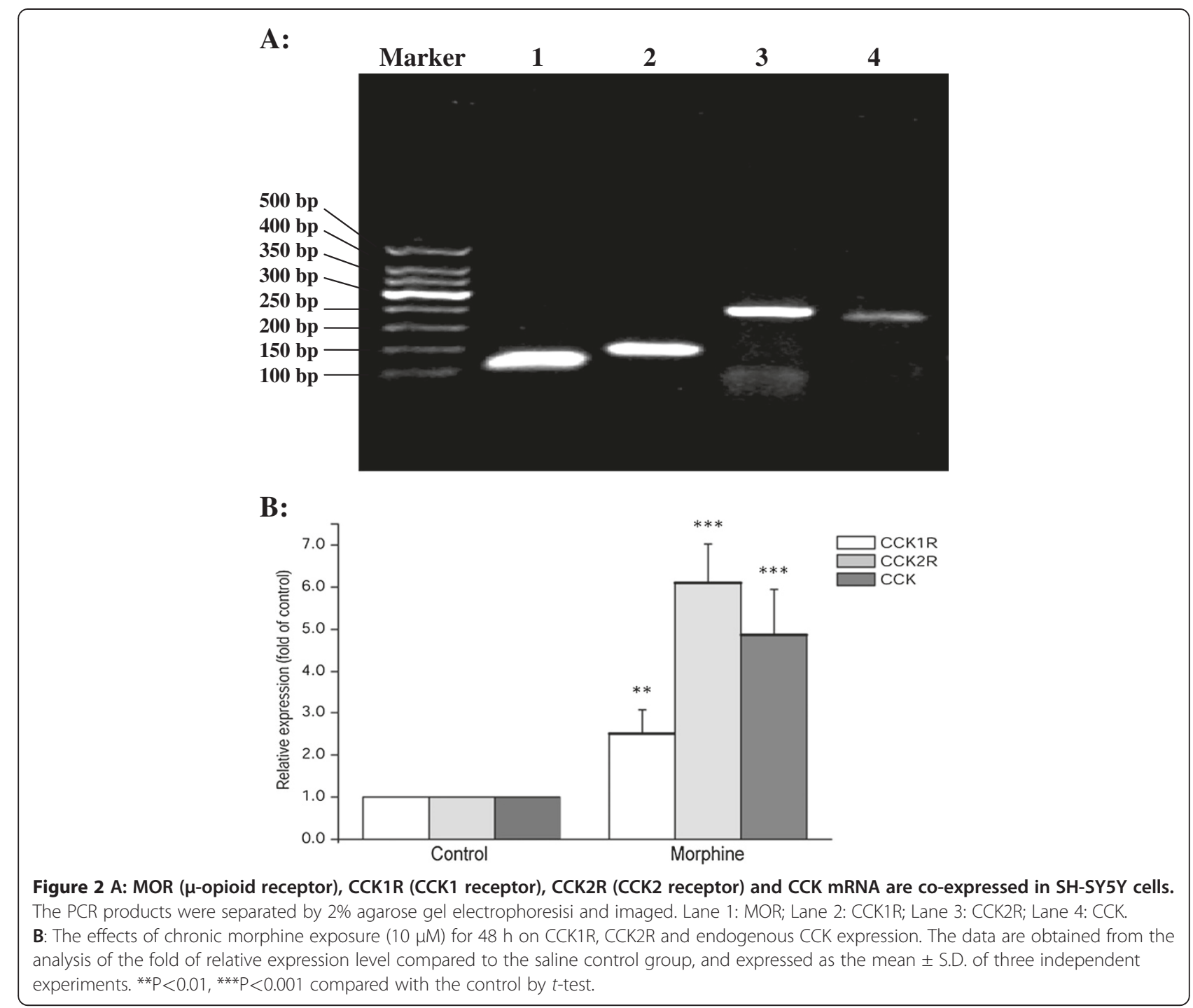

after chronic morphine treatment. Therefore, L-364,718, a CCK1 receptor antagonist, and LY-288,513, a CCK2 receptor antagonist $(0.01-10 \mu \mathrm{M})$, were utilised to examine endogenous CCK regulation of the development of morphine dependence in SH-SY5Y cells. Baseline experiments were first conducted in the absence of the opioid. Pretreatment with L-364,718 $\left(\mathrm{F}_{4,10}=0.593, P=0.676\right)$ or LY-288,513 $\left(\mathrm{F}_{4,10}=0.246, P=0.905\right)$ alone did not affect cellular basal cAMP levels (Figure 3A). Copretreatment of LY-288,513 (1 and $10 \mu \mathrm{M})$ with morphine $(10 \mu \mathrm{M})$ for $48 \mathrm{~h}$ significantly inhibited cAMP overshoot following naloxone $(10 \mu \mathrm{M}, 15 \mathrm{~min})$ precipitation $\left(\mathrm{F}_{4,10}=22.185, P<0.001\right.$, Figure $\left.3 \mathrm{~B}\right)$, however, L-364,718 exhibited no effect $\left(\mathrm{F}_{4,10}=0.119, P=0.972\right.$, Figure $3 \mathrm{~B})$. Consistent with a previous study in vivo, these findings suggest that endogenous CCKs have a notable effect on morphine dependence in vitro via the CCK2 receptor.
The effect of exogenous CCK-8 on naloxone-precipitated cAMP overshoot in SH-SY5Y cells after chronic morphine exposure

Exogenous CCK-8 (0.1-1 $\mu \mathrm{M})$, a CCK receptor agonist, inhibited the naloxone $(10 \mu \mathrm{M})$ precipitated cAMP overshoot when co-pretreated with morphine $(10 \mu \mathrm{M} ; 48 \mathrm{~h})$ $\left(\mathrm{F}_{4,10}=8.914, P=0.002\right.$, Figure $\left.4 \mathrm{~B}\right)$ in a dose-dependent manner, indicating that exogenous CCK-8 has an identical regulatory effect on cellular morphine dependence as the antagonist. A significant inhibitory effect was observed at a concentration of $0.1 \mu \mathrm{M}(P=0.028)$ and $1 \mu \mathrm{M} \quad(P=0.011)$, but not at $0.001 \mu \mathrm{M}$ or $0.1 \mu \mathrm{M}$ $(P=0.722, P=0.967)$, compared with the morphine pretreated control cells. Baseline experiments were conducted in the absence of the opioid. Treatment with CCK-8 at concentrations from 0.001 to $1 \mu \mathrm{M}$ for $48 \mathrm{~h}$ exhibited no effect on basal cAMP levels $\left(\mathrm{F}_{4,10}=0.132\right.$, $P=0.967$, Figure 4A). Moreover, exogenous CCK-8 did 

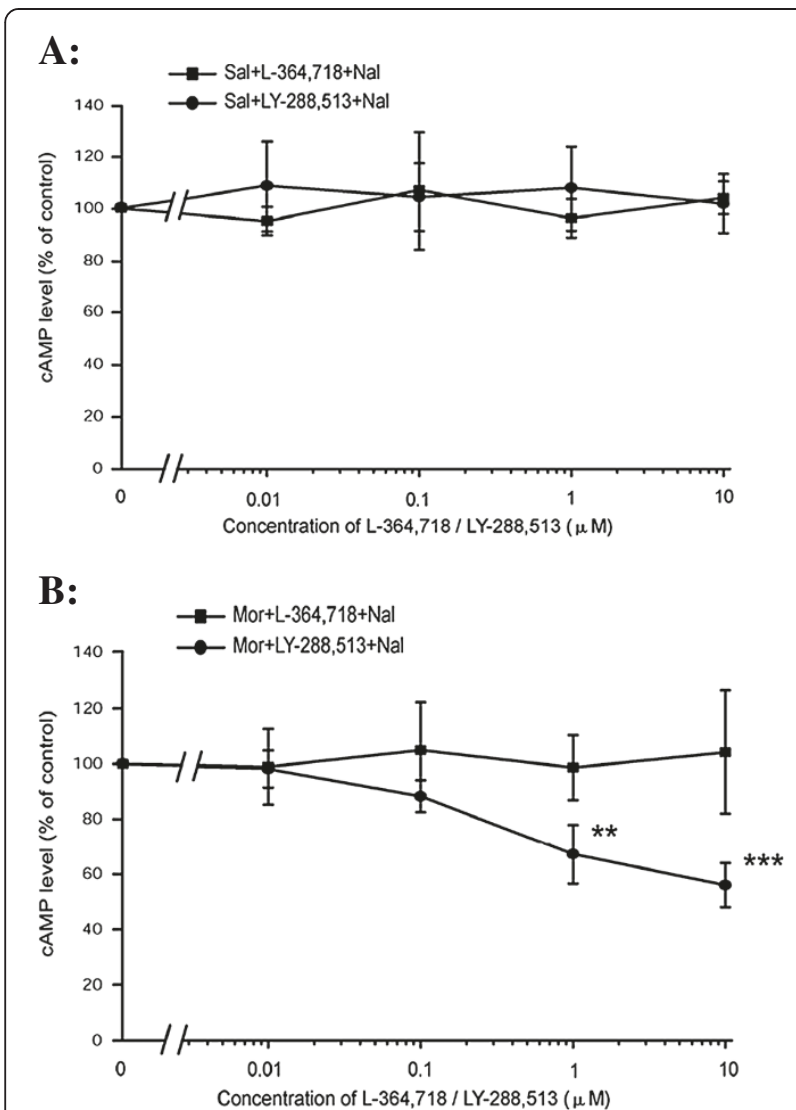

Figure 3 The effect of L-364,718 or LY-288,513 on naloxone precipitated CAMP overshoot in saline (A) or morphine (B) pretreated SH-SY5Y cells. The SH-SY5Y cells were first COpretreated with $\mathrm{L}-364,718$ or LY-288,513 $(0-10 \mu \mathrm{M})$ and saline for 48 $h$ to evaluate the effect of CCK receptor antagonists on the baseline CAMP level, and then incubated with L-364,718 or LY-288,513 plus morphine $(10 \mu \mathrm{M})$ to investigate the influence of CCK receptor antagonists on the naloxone (10 $\mu \mathrm{M}, 15 \mathrm{~min})$ precipitated CAMP overshoot. The control groups were considered as no CCK receptor antagonist-treated cells ( 0 MM L-364,718/LY-288,513) in each independent experiment. The results of the CAMP levels are represented as the percentage of CAMP content relative to the control group. The data are presented as the mean \pm S.D. of three separate experiments, performed in duplicate. ${ }^{* *} P<0.01$, ${ }^{* * *} P<$ 0.01 , compared with the control by one-way ANOVA followed by Dunnett's t-test.

not alter the forskolin stimulated cAMP levels $\left(\mathrm{F}_{4}\right.$, $10=2.685, P=0.094$, Figure $4 C$ ), indicating that a nonspecific inhibitory mechanism on cAMP shoot induced by CCK- 8 could be ruled out.

\section{Blockade of the CCK1 receptor attenuates the effect of exogenous CCK-8 on naloxone-precipitated CAMP overshoot after chronic morphine exposure}

As described above, CCK-8 (0.1-1 $\mu \mathrm{M})$ inhibited naloxone precipitated cAMP overshoot when co-pretreated with morphine in a dose-dependent manner. We then blocked CCK1 and CCK2 receptors using L-364,718 and
LY-288,513, respectively, to determine the role of CCK receptor subtypes in exogenous CCK-8 regulating morphine dependence. The cells were pre-treated with L-364,718 (1 and $10 \mu \mathrm{M})$ or LY-288,513 (1 and $10 \mu \mathrm{M})$, $15 \mathrm{~min}$ before co-treatment of morphine $(10 \mu \mathrm{M})$ and CCK-8 $(1 \mu \mathrm{M})$. Next, the cAMP overshoot was subsequently induced by adding $10 \mu \mathrm{M}$ naloxone. The inhibitory effect of CCK- 8 on the naloxone precipitated cAMP overshoot was significantly reduced at both $1 \mu \mathrm{M}$ $(P=0.003)$ and $10 \mu \mathrm{M}(P<0.001)$ L-364,718 pre-treated cells (Figure 5). However, no change was observed in $1 \mu \mathrm{M}(P=0.373)$ and $10 \mu \mathrm{M}(P=0.069)$ LY-288,513 pretreated cells, indicating that the CCK1 receptor mediated the effect of exogenous CCK-8 on cellular morphine dependence. Due to the inhibitory function of LY-288,513 and CCK-8 on the CAMP overshoot (Figure 3 and Figure 4), a cumulative effect of LY-288,513 and exogenous CCK-8 was not observed.

\section{Discussion}

In this present study, we describe a distinct effect of exogenous CCK-8 on the development of morphine dependence in vitro. Moreover, we provide the first piece of evidence that a CCK1 receptor antagonist can reverse the inhibitory effects of exogenous CCK- 8 on morphine dependence. We also find that endogenous CCK exerts a potential facilitative effect via the CCK2 receptor. This suggests opposing roles of CCK1 and CCK2 receptors in the development of morphine dependence.

First, a suitable cell model was selected for this study. The SH-SY5Y cell line is derived from a human neuroblastoma cell line, SK-N-SH, by three rounds of subcloning. The SH-SY5Y cells are dopamine beta hydroxylase active, acetylcholinergic, glutamatergic and adenosinergic, and express abundant and functional $\mu$ - and $\delta$-opioid receptors. SH-SY5Y cells have been extensively used for studies of opioid receptor regulation and intracellular signaling. Moreover, co-expression of the opioid and CCK systems in SH-SY5Y cells was confirmed, and CCK is endogenously expressed in SH-SY5Y cells. This system is useful for the study of the potential regulatory effects of exogenous CCK-8 on morphine dependence.

The interaction between CCK and opioids was first reported by Itoh et al. They showed that pre-treatment with CCK suppressed anti-nociception induced by $\beta$ endorphin [29]. A subsequent in vivo microdialysis study found that the extracellular levels of CCK significantly increased after morphine administration, thus acting as a negative feedback modulator and a potent anti-opioid peptide $[6,7,30]$. Studies have confirmed that endogenous CCK potentiates, and the CCK antagonist attenuates the tolerance and dependence of opioids [31,32]. The presence of opioid receptors in CCK-containing neurons suggest a potential direct influence of opioids on CCK 

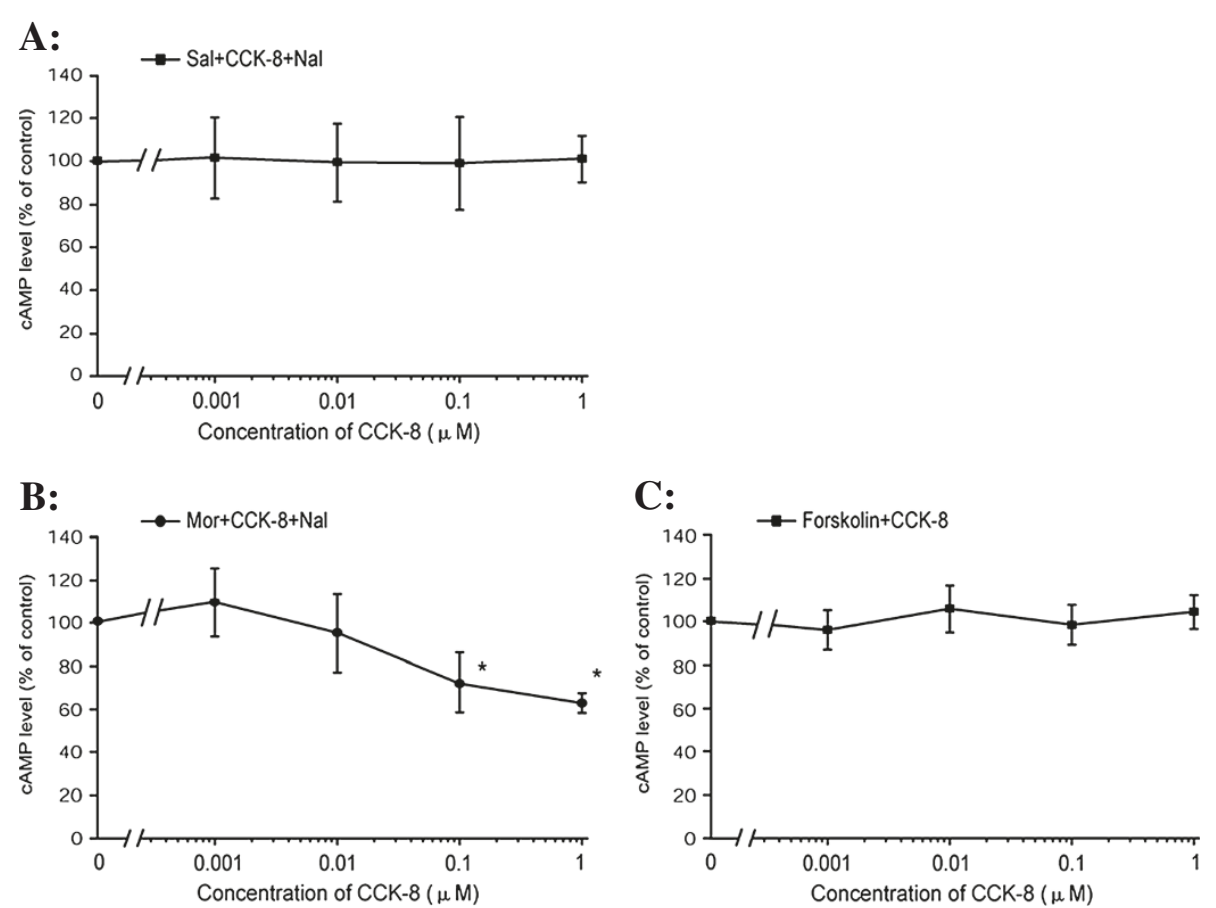

Figure 4 The effects of CCK-8 on saline (A) or morphine (B) pretreated, naloxone precipitated cAMP overshoot and, on forskolin stimulated CAMP accumulation (C) in SH-SY5Y cells. The SH-SY5Y cells were co-pretreated with CCK-8 (0.001-10 $\mu$ M) and saline or $10 \mu \mathrm{M}$ morphine for $48 \mathrm{~h}$ to observe the effect of exogenous CCK-8 on the baseline CAMP levels and morphine withdrawal-induced CAMP overshoot, respectively. The cells were then co-pretreated with CCK-8 (0.001-10 $\mu \mathrm{M})$ and forskolin $(10 \mu \mathrm{M})$ to rule out non-specific inhibition of CCK-8 on the CAMP overshoot. The control groups were as the cells that received no CCK-8 (0 $\mu$ M CCK-8) treatment in each independent experiment. The results of the CAMP levels are represented as the percentage of CAMP content relative to the control group. The data are presented as the mean \pm S.D. of three separate experiments, performed in duplicate. ${ }^{*} P<0.05$, compared with the control by one-way ANOVA followed by Dunnett's t-test.

release [33]. However, earlier studies have failed to show an affinity of CCK for opioid receptors, indicating that CCK does not behave as a classical receptor antagonist via binding to opioid receptors [34]. Han et al. found that the binding of CCK- 8 to the CCK receptor reduces the binding affinity of $\mu$-opioid receptor ligands, implying that receptor-receptor interaction between CCK and opioid systems may occur in an indirect manner [35]. The molecular cloning of CCK receptor subtypes, one from the pancreas (type-1) and another from human brain (type-2), has confirmed the pharmacological classification of CCK receptors. The CCK2 receptor is predominantly localised in the CNS, and mainly mediates anxiety, panic attacks, pain and drug dependence [3638]. The CCK 1 receptor is present in discrete regions of the brain and has a low affinity for central CCK [39], and its function is poorly understood with only a few reports investigating the central role in food intake regulation [40]. The use of highly selective receptor antagonists and antisense approaches has shown, at least in the rodent, that CCK2 receptors mediate the antiopioid function of CCK [41-43]. The present study shows that co-pretreatment with LY-288,513 and morphine significantly inhibited the naloxone-precipitated cAMP overshoot in SH-SY5Y cells, but that co-pretreatment with L-364,718 displayed no effect. We verified that endogenous CCK played an anti-opioid role and potentiated the development of morphine dependence via the CCK2 receptor.

Together with our previous results, we found that exogenous CCK-8 pretreatment significantly inhibited morphine dependence in vitro and in vivo [44]. These results show that the treatments of the CCK receptor agonist and antagonist demonstrated the same effect on morphine dependence. Moreover, CCK- 8 treatment did not affect basal or forskolin-stimulated cAMP levels, suggesting that the effect of exogenous CCK- 8 was not simply a direct action on cAMP. Several studies have reported that small doses of CCK inhibit the antinociceptive action of opioids, whereas large doses of CCK induce analgesia [45]. We previously revealed that CCK-8 suppressed the binding affinity of the $\mu$-opioid receptor in SH-SY5Y cells at concentrations of $1 \mathrm{nM}$, while it increased the expression of the endogenous opioid peptide from 0.1 to $1 \mu \mathrm{M}$ [46]. The dose-response curve of CCK- 8 was inversely U-shaped, and CCK-8 


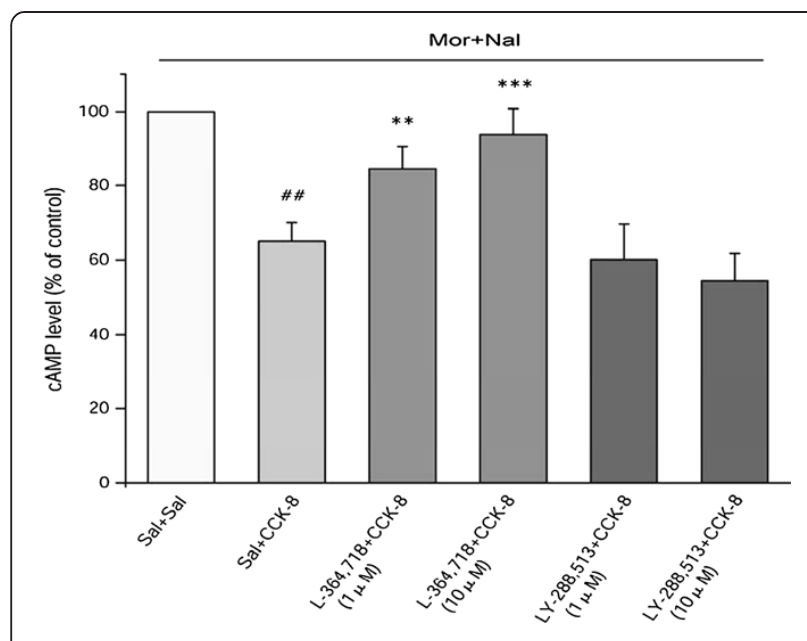

Figure 5 The CCK1 receptor antagonist blocked the inhibitory effects of exogenous CCK-8 on naloxone precipitated CAMP overshoot after chronic morphine exposure. The SH-SY5Y cells were co-pretreated with L-364,718(1 and $10 \mu \mathrm{M})$ or LY-288,513(1 and $10 \mu \mathrm{M})$ and CCK-8 $(1 \mu \mathrm{M})$ plus morphine $(10 \mu \mathrm{M})$ for $48 \mathrm{~h}$. After the removal of the drugs, naloxone $(10 \mu \mathrm{M}, 15 \mathrm{~min})$ was added for the induction of the CAMP overshoot. The control group was the no CCK- 8 and CCK receptor antagonist treated cells (Sal + Sal). The results of the CAMP level are represented as the percentage of CAMP content relative to the control group. The data are the mean \pm S.D. of three separate experiments, performed in duplicate. \#\#P $<0.01$, compared with the Sal + Sal group by $t$-test; ${ }^{* * P}<0.01$, ${ }^{* * *} P<$ 0.001 as compared with the Sal + CCK-8 group by one-way ANOVA followed by Dunnett's t-test.

displayed a dose-dependent, biphasic effect [47]. We found that only high concentrations of CCK- 8 were able to attenuate the cAMP overshoot in a dose-dependent manner. Thus, observations of exogenous CCK- 8 may represent pharmacological effects, rather than physiological effects of endogenous CCK.

A previous study indicated that the CCK1 receptor was ineffective in the development of morphine dependence [42]. Nevertheless, we found that a high dose of exogenous CCK-8 markedly attenuated the naloxone precipitated cAMP overshoot via the CCK1 receptor. We concluded that the CCK1 and CCK2 receptors play unique and distinct roles in physiology and pathophysiology. Moreover, data showing that CCK1 receptors mediate mnemonic effects, and that CCK2 receptors mediate amnestic effects, have been reported [48]. Furthermore, CCK evokes $\left[\mathrm{Ca}^{2+}\right]_{\mathrm{i}}$ signaling by the influx of extracellular calcium, likely through L-type calcium channels, and an antagonist for the CCK1 receptor blocked $\left[\mathrm{Ca}^{2+}\right]_{i}$ response to CCK-8 $[49,50]$. CCK produces direct neuronal depolarisation via CCK1 receptors and inhibits GABAergic synaptic transmission [51], while CCK2 receptor activation augments long-term potentiation in hippocampal slices [52]. CCK-8, the predominant central form of CCK, has a high affinity for the
CCK2 receptor, but a low affinity for the CCK1 receptor. The CCK1 receptor is activated only in the presence of high CCK- 8 levels, and exerts a different effect from the CCK2 receptor on morphine dependence. Due to the inhibitory function of LY-288,513 and CCK- 8 on cAMP overshoot, the cumulative effect of LY-288,513 and exogenous CCK-8 on cAMP overshoot was not observed. The role of CCK2 receptor in the process of exogenous CCK-8 regulation on morphine dependence can not be ruled out.

\section{Conclusions}

In conclusion, we identified a difference between the role of the CCK1 and CCK2 receptor on the development of morphine dependence and an inhibitory effect of high-doses of exogenous CCK- 8 on cellular morphine dependence. In addition, this study provides the first evidence for the participation of the CCK1 receptor in the mechanism by which exogenous CCK- 8 inhibits morphine dependence.

\section{Materials and methods Materials}

Morphine hydrochloride was purchased from Shenyang First Pharmaceutical Factory (Liaoning, China). CCK-8, IBMX, naloxone and forskolin were purchased from Sigma (Sigma, St. Louis, MO, USA). Retinoic acid (RA) was purchased from Alfa Aesar (Alfa Aesar, Heysham, UK). The CCK1 receptor antagonist, L-364,718, and CCK2 receptor antagonist, LY-288,513, were purchased from Tocris Bioscience (Tocris Cookson, Northpoint, UK). DMEM/F12 medium was purchased from Invitrogen Corporation (Gibco ${ }^{\mathrm{Tm}}$, Grand Island, NY, USA). Fetal bovine serum was purchased from PAA Laboratories (PAA, Strasse, Pasching, Austria). LANCE ${ }^{\mathrm{Tm}}$ cAMP kits were purchased from PerkinElmer (PerkinElmer, MA, USA). CCK- 8 was suspended in vehicle consisting of $1 \%$ ammonia saline solution at $1 \mathrm{mg} / \mathrm{ml}$, and the CCK receptor antagonists were suspended in DMSO at $1 \mathrm{mg} / \mathrm{ml}$.

\section{Cell culture}

Human SH-SY5Y neuroblastoma cells were obtained from Shanghai Bioleaf Biotec (Shanghai, China). The cells were seeded at $1 \times 10^{6}$ cell $/ 25 \mathrm{~cm}^{2}$ in tissue culture flasks and grown in DMEM/F12 medium supplemented with $10 \%$ fetal bovine serum, $100 \mathrm{U} / \mathrm{ml}$ penicillin and $100 \mathrm{U} / \mathrm{ml}$ streptomycin for 24 hours. The cells were then morphologically differentiated into neuron-like cells by treatment with10 mM RA. Similar with previous studies [53], the RA-containing medium was replaced every 2 days. The cultured SH-SY5Y cells were then used for experiments 6 days after the initiation of differentiation. All of the cultures were maintained at $37{ }^{\circ} \mathrm{C}$ in a humidified atmosphere consisting of $95 \%$ air and $5 \% \mathrm{CO}_{2}$. 
Table 1 Primer sequences used for real-time PCR

\begin{tabular}{|c|c|c|}
\hline Gene & Sense & Anti-sense \\
\hline MOR & 5'-ATCACGATCATGGCCCTCTACTCC-3' & 5'-TGGTGGCAGTCTTCATCTTGGTGT-3 \\
\hline CCK1R & 5'-GACGCTTCGGTCATTAGA-3' & 5'-AGGGAGGAGTGATGTTGC-3' \\
\hline CCK2R & 5'-CCСACTCCCTCCATTGCT-3' & 5'-CTGCTCCATTCTTATTCCTCTT-3' \\
\hline CCK & 5'-AGCTGAGGGTATCGCAGAGA-3' & 5'-TGGGTCCTCTAGGAGGGGTA-3' \\
\hline$\beta$-actin & 5'-GGGACCT GACTGACTACCTC-3' & 5'-ACTCGTCATACTCCTGCTTG-3' \\
\hline
\end{tabular}

\section{Real-time PCR analysis}

The cells were harvested and the total RNA was extracted with TriZol Reagent (Invitrogen, Carlsbad, CA) according to the manufacturer's instructions. The RNA concentrations were determined using a Nanodrop ND-1000 spectrophotometer (Nanodrop Technologies, Wilmington, DE, USA), and the complementary DNA (cDNA) was synthesised from the total RNA (500 ng) using the PrimeScript ${ }^{\mathrm{Tm}}$ RT regent Kit (Takara Biotechnology, Dalian, China) following the instructions provided by the manufacturer. Subsequently, the cDNA was subjected to real-time PCR using the Power SYBR Green PCR Master Mix (Takara Biotechnology, Dalian, China). Each real-time PCR reaction consisted of $2 \mu \mathrm{l}$ of diluted RT product, $10 \mu \mathrm{l}$ SYBR Green PCR Master Mix and 250-nm specific primer pairs (Table 1 ) in a total volume of $20 \mu \mathrm{l}$. The reactions were performed on a 7500 realtime PCR System (Applied Biosystems) for 40 cycles $\left(95{ }^{\circ} \mathrm{C}\right.$ for $5 \mathrm{~s}, 60{ }^{\circ} \mathrm{C}$ for $35 \mathrm{~s}$ ) after an initial $30 \mathrm{~s}$ incubation at $95{ }^{\circ} \mathrm{C}$. The PCR products were separated by $2 \%$ agarose gel electrophoresis, illuminated with UV light and imaged to assess the amplification. The fold change in the mRNA levels of each gene was calculated using the $\Delta \Delta \mathrm{Ct}$ method, with the house keeping gene, $\beta$-actin, as an internal control.

\section{cAMP accumulation assays}

The differentiated SH-SY5Y cells that had been treated with morphine and/or CCK-8 for $48 \mathrm{~h}$ were assayed for cAMP accumulation using a $\mathrm{LANCE}^{\mathrm{m}}$ cAMP kit (PerkinElmer). The cells were harvested with a Versene dissociation solution followed by washing with HBSS buffer. The cells were then resuspended at a concentration of $2 \times 10^{6}$ cells $/ \mathrm{ml}$ in stimulation buffer (HBSS $1 \times$, containing $5 \mathrm{mM}$ HEPES, 0.1\% BSA, $0.05 \mathrm{mM}$ IBMX). The Alexa pluor ${ }^{\circledR} 647$ labeled antibodies were added to the final cell suspension, and then naloxone was added to the cell suspension to precipitate the cAMP overshoot. After incubation at $37{ }^{\circ} \mathrm{C}$ for $15 \mathrm{~min}$, the Detection Mix was added to the mixture. The sample was further incubated for $1 \mathrm{~h}$, and was read on a TECAN instrument (Infinitie F200, Tecan, Grodig, Austria) to measure the LANCE signal. Simultaneous to the measurement of the cell-based cAMP level, the cAMP standard curve was assayed according to the manufacturer's instructions. The LANCE signal obtained at $665 \mathrm{nM}$ can be directly used to analyse the cAMP levels. The signal at $615 \mathrm{nM}$ is useful to identify dispensing or quenching problems.

\section{Statistical analysis}

The data are presented as the mean \pm standard deviation (S.D.) All of the experiments were performed at least three times, each with a different culture. The statistical analyses (SPSS, v. 13.0, Chicago, USA) were performed with two-way ANOVA to evaluate the interaction between morphine and naloxone on the cAMP overshoot to estabish the cellular model of morphine dependence, and then with $t$-test and one-way ANOVA followed by Dunnett's $t$-test for subsequent experiments. A $P$-value $<0.05$ was considered statistically significant.

\section{Acknowledgments}

This study was supported, in part, by the grants obtained from the Natural Science Foundation of China (No. 81172900, 30672355), the Applied Basic Research Key Program of Hebei Province (No. 10966911D) and the Natural Science Foundation of Hebei Province (No. C2007000826).

\section{Author details}

${ }^{1}$ Department of Forensic Medicine, Hebei Medical University, Hebei Key Laboratory of Forensic Medicine, Shijiazhuang 050017, PR China. ${ }^{2}$ The First Hospital of Shijiazhuang, Shijiazhuang 050011, PR China.

\section{Authors' contributions}

All of the authors contributed to the writing of the manuscript and approved of the final version. DW performed the experiments and data analysis, participated in the design of the study and drafted the manuscript. CLM and BC conceived of and designed the study and supervised the work. YJZ and YXM contributed to the design of the study, and helped with performing the experiments and drafting the manuscript. ZYN and SJL provided intellectual input to the study and helped with the revision of the manuscript. All authors read and approved the final manuscript

Received: 15 November 2011 Accepted: 8 June 2012

Published: 8 June 2012

\section{References}

1. Su RB, Lu XQ, Huang Y, Liu Y, Gong ZH, Wei XL, Wu N, Li J: Effects of intragastric agmatine on morphine-induced physiological dependence in beagle dogs and rhesus monkeys. Eur J Pharmacol 2008, 587(1-3):155-162.

2. Rezayof A, Nazari-Serenjeh F, Zarrindast MR, Sepehri H, Delphi L: Morphineinduced place preference: involvement of cholinergic receptors of the ventral tegmental area. Eur J Pharmacol 2007, 562(1-2):92-102.

3. Cesselin F: Opioid and anti-opioid peptides. Fundam Clin Pharmacol 1995, 9(5):409-433.

4. Crawley JN, Corwin RL: Biological actions of cholecystokinin. Peptides 1994, 15(4):731-755. 
5. Faris PL, Komisaruk BR, Watkins LR, Mayer DJ: Evidence for the neuropeptide cholecystokinin as an antagonist of opiate analgesia. Science 1983, 219:310-312.

6. Benoliel JJ, Mauborgne A, Bourgoin S, Legrand JC, Hamon M, Cesselin F: Opioid control of the in vitro release of cholecystokinin-like material from the rat substantia nigra. J Neurochem 1992, 58(3):916-922.

7. Becker C, Pohl M, Thiebot MH, Collin E, Hamon M, Cesselin F, Benoliel JJ: Delta-opioid receptor-mediated increase in cortical extracellular levels of cholecystokinin-like material by subchronic morphine in rats. Neuropharmacology 2000, 39(2):161-171.

8. DeSantana JM, da Silva LF, Sluka KA: Cholecystokinin receptors mediate tolerance to the analgesic effect of TENS in arthritic rats. Pain 2010, 148(1):84-93.

9. Ma KT, Si JQ, Zhang ZQ, Zhao L, Fan P, Jin JL, Li XZ, Zhu L: Modulatory effect of CCK-8S on GABA-induced depolarization from rat dorsal root ganglion. Brain Res 2006, 1121(1):66-75.

10. Van Kampen J, Frydryszak H, Stoessl AJ: Behavioural evidence for cholecystokinin-dopamine D1 receptor interactions in the rat. Eur $\mathrm{J}$ Pharmacol 1996, 298(1):7-15.

11. Tanganelli S, Fuxe K, Antonelli T, O'Connor WT, Ferraro L: Cholecystokinin/ dopamine/GABA interactions in the nucleus accumbens: biochemical and functional correlates. Peptides 2001, 22(8):1229-1234.

12. Phillips GD, Le Noury J, Wolterink G, Donselaar-Wolterink I, Robbins TW, Everitt $B J$ : Cholecystokinin-dopamine interactions within the nucleus accumbens in the control over behaviour by conditioned reinforcement. Behav Brain Res 1993, 55(2):223-231.

13. Larsson LI, Rehfeld JF: Localization and molecular heterogeneity of cholecystokinin in the central and peripheral nervous system. Brain Res 1979, 165(2):201-218.

14. Lu L, Huang M, Liu Z, Ma L: Cholecystokinin-B receptor antagonists attenuate morphine dependence and withdrawal in rats. Neuroreport 2000, 11(4):829-832.

15. Huang C, Hu ZP, Jiang SZ, Li HT, Han JS, Wan Y: CCK(B) receptor antagonist $L 365,260$ potentiates the efficacy to and reverses chronic tolerance to electroacupuncture-induced analgesia in mice. Brain Res Bull 2007, 71(5):447-451.

16. Dourish CT, O'Neill MF, Coughlan J, Kitchener SJ, Hawley D, Iversen SD: The selective CCK-B receptor antagonist L-365,260 enhances morphine analgesia and prevents morphine tolerance in the rat. Eur J Pharmacol 1990, 176(1):35-44

17. Rezayat M, Nikfar S, Zarrindast MR: CCK receptor activation may prevent tolerance to morphine in mice. Eur J Pharmucol 1994, 254(1-2):21-26.

18. Wen D, Ma CL, Cong B, Zhang YJ, Yang SC, Meng YX, Yu F, Ni ZY, Li SJ: Effects of CCK- 8 and its receptor antagonists given intracerebroventricularly on withdrawal symptom of morphine dependent rats. Chin Pharmacol Bull 2011, 27(10):1368-1373.

19. Wen D, Ma CL, Cong B, Zhang YJ, Yang SC, Yu F, Ni ZY, Li SJ: Effects of CCK-8 and its receptor antagonists on opioid receptor in prefrontal cortex, cauduate putamen and hippocampus of morphine withdrawal rats. Chin Pharmacol Bull 2010, 26:867-871.

20. Rezayat M, Azizi N, Zarrindast MR: On the mechanism(s) of cholecystokinin (CCK): receptor stimulation attenuates morphine dependence in mice. Pharmacol Toxicol 1997, 81(3):124-129.

21. Wank SA: Cholecystokinin receptors. Am J Physiol 1995, 269(5 Pt 1):G628-G646.

22. Woodruff GN, Hill DR, Boden P, Pinnock R, Singh L, Hughes J: Functional role of brain CCK receptors. Neuropeptides 1991, 19(Suppl):45-56.

23. Mannisto PT, Lang A, Harro J, Peuranen E, Bradwejn J, Vasar E: Opposite effects mediated by CCKA and CCKB receptors in behavioural and hormonal studies in rats. Naunyn Schmiedebergs Arch Pharmacol 1994, 349 (5):478-484

24. Noble F, Roques BP: Phenotypes of mice with invalidation of cholecystokinin (CCK(1) or CCK(2)) receptors. Neuropeptides 2002, 36(2-3):157-170

25. Koob GF, Bloom FE: Cellular and molecular mechanisms of drug dependence. Science 1988, 242(4879):715-723.

26. Nestler EJ: Historical review: Molecular and cellular mechanisms of opiate and cocaine addiction. Trends Pharmacol Sci 2004, 25(4):210-218.

27. Charles AC, Hales TG: From inhibition to excitation: functional effects of interaction between opioid receptors. Life Sci 2004, 76(5):479-485.

28. Xia M, Guo V, Huang R, Shahane SA, Austin CP, Nirenberg M, Sharma SK: Inhibition of morphine-induced CAMP overshoot: a cell-based assay model in a high-throughput format. Cell Mol Neurobiol 2011, 31(6):901-907.

29. Itoh S, Katsuura G, Maeda Y: Caerulein and cholecystokinin suppress betaendorphin-induced analgesia in the rat. Eur J Pharmacol 1982, 80(4):421-425.

30. You ZB, Tzschentke TM, Brodin E, Wise RA: Electrical stimulation of the prefrontal cortex increases cholecystokinin, glutamate, and dopamine release in the nucleus accumbens: an in vivo microdialysis study in freely moving rats. J Neurosci 1998, 18(16):6492-6500.

31. Herranz R: Cholecystokinin antagonists: pharmacological and therapeutic potential. Med Res Rev 2003, 23(5):559-605.

32. Mitchell JM, Bergren LJ, Chen KS, Fields HL: Cholecystokinin is necessary for the expression of morphine conditioned place preference. Pharmacol Biochem Behav 2006, 85:787-795.

33. Yan YX, Hu WL, Cong B, Ma CL, Ni ZY, Niu ZQ, Yu L: Expressions of $\mu$ opioid receptor and CCK receptor in rat primary hippocampal neurons and effect of chronic morphine exposure on them. J Fourth MilMed Univ 2007, 28(13):1214-1217.

34. Wang XJ, Fan SG, Ren MF, Han JS: Cholecystokinin-8 suppressed 3Hetorphine binding to rat brain opiate receptors. Life Sci 1989, 45(2):117-123.

35. Wang XJ, Han JS: Modification by cholecystokinin octapeptide of the binding of mu-, delta-, and kappa-opioid receptors. J Neurochem 1990 55(4):1379-1382.

36. Moran TH, Schwartz GJ: Neurobiology of cholecystokinin. Crit Rev Neurobiol 1994, 9(1):1-28.

37. Pommier B, Beslot F, Simon A, Pophillat M, Matsui T, Dauge V, Roques BP, Noble F: Deletion of CCK2 receptor in mice results in an upregulation of the endogenous opioid system. J Neurosci 2002, 22(5):2005-2011.

38. Dauge V, Sebret A, Beslot F, Matsui T, Roques BP: Behavioral profile of CCK2 receptor-deficient mice. Neuropsychopharmacology 2001 25(5):690-698

39. Mercer LD, Beart PM: Histochemistry in rat brain and spinal cord with an antibody directed at the cholecystokininA receptor. Neurosci Lett 1997 225(2):97-100

40. Voigt JP, Huston JP, Voits M, Fink H: Effects of cholecystokinin octapeptide (CCK-8) on food intake in adult and aged rats under different feeding conditions. Peptides 1996, 17(8):1313-1315.

41. Alttoa A, Harro J: Effect of CCK1 and CCK2 receptor blockade on amphetamine-stimulated exploratory behavior and sensitization to amphetamine. Eur Neuropsychopharmacol 2004, 14(4):324-331.

42. Lu L, Huang M, Ma L, Li J: Different role of cholecystokinin (CCK)-A and CCK-B receptors in relapse to morphine dependence in rats. Behav Brain Res 2001, 120(1):105-110.

43. Noble F, Roques BP: The role of CCK2 receptors in the homeostasis of the opioid system. Drugs Today (Barc) 2003, 39(11):897-908.

44. Wen D, Cong B, Ma C, Yang S, Yu H, Ni Z, Li S: The effects of exogenous CCK-8 on the acquisition and expression of morphine-induced CPP. Neurosci Lett 2012, 510(1):24-28.

45. Doi T, Jurna I: Analgesic effect of intrathecal morphine demonstrated in ascending nociceptive activity in the rat spinal cord an in effectiveness of caerulein and cholecystokinin octapeptide. Brain Res 1982, 234(2):399-407.

46. Wen D, Ma CL, Cong B, Yu HL, Yu F, Ni ZY, Li SJ: Interaction of CCK-8 and endogenous opioid system in the opioid dependence. Chin Pharmacol Bull 2010, 26(11):421-426.

47. Heinricher MM, Neubert MJ: Neural basis for the hyperalgesic action of cholecystokinin in the rostral ventromedial medulla. J Neurophysio/ 2004 92(4):1982-1989.

48. Hadjiivanova C, Belcheva S, Belcheva I: Cholecystokinin and learning and memory processes. Acta Physiol Pharmacol Bulg 2003, 27(2-3):83-88.

49. Zhang W, Segura BJ, Mulholland MW: Cholecystokinin-8 induces intracellular calcium signaling in cultured myenteric neurons from neonatal guinea pigs. Peptides 2002, 23(10):1793-1801.

50. Lankisch TO, Tsunoda Y, Lu Y, Owyang C: Characterization of CCK(A) receptor affinity states and $\mathrm{Ca}(2+)$ signal transduction in vagal nodose ganglia. Am J Physiol Gastrointest Liver Physiol 2002, 282(6):G1002-G1008.

51. Mitchell VA, Jeong HJ, Drew GM, Vaughan CW: Cholecystokinin exerts an effect via the endocannabinoid system to inhibit GABAergic transmission in midbrain periaqueductal gray. Neuropsychopharmacology 2012, 36(9):1801-1810. 
52. Yasui M, Kawasaki K: CCKB-receptor activation augments the long-term potentiation in guinea pig hippocampal slices. Jpn J Pharmacol 1995, 68(4):441-447.

53. Fang F, Cao Q, Song F, Liu J: Effects of long-term morphine exposure on the CAMP system and c-Fos phosphorylation in differentiated SH-SY5Y cells. Zhongguo Yi Xue Ke Xue Yuan Xue Bao 1999, 21(4):262-267.

doi:10.1186/1471-2202-13-63

Cite this article as: Wen et al: Cholecystokinin receptor-1 mediates the inhibitory effects of exogenous cholecystokinin octapeptide on cellular morphine dependence. BMC Neuroscience 2012 13:63.

\section{Submit your next manuscript to BioMed Central and take full advantage of:}

- Convenient online submission

- Thorough peer review

- No space constraints or color figure charges

- Immediate publication on acceptance

- Inclusion in PubMed, CAS, Scopus and Google Scholar

- Research which is freely available for redistribution 